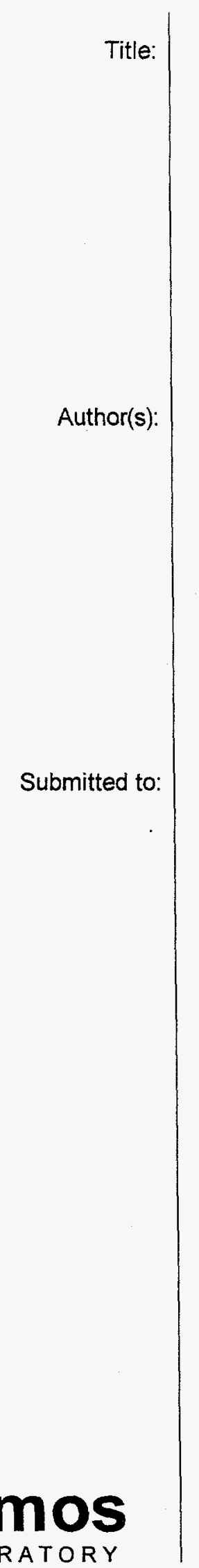

Advanced Industrial Materials (AIM)

Program, Final Report, FY1997

"Microwave Processing of Ceramic Oxide Filaments"

Gerald J. Vogt

Dr. Charles Sorrell

Program Manager

Advanced Industrial Materials Program office of Industrial Technology

US Department of Energy

CE-232, Room 5E-066, Forrestal Building 1000 Independence Avenue, SW

Washington, DC 20585

Los Alamos National Laboratory, an affirmative action/equal opportunity employer, is operated by the University of California for the U.S. Department of Energy under contract W-7405-ENG-36. By acceptance of this article, the publisher recognizes that the U.S. Government retains a nonexclusive, royalty-free license to publish or reproduce the published form of this contribution, or to allow others to do so, for U.S. Government purposes. Los Alamos National Laboratory requests that the publisher identify this article as work performed under the auspices of the U.S. Department of Energy. The Los Alamos National Laboratory strongly supports academic freedom and a researcher's right to publish; as an institution, however, the Laboratory does not endorse the viewpoint of a pubiication or guarantee its technical correctness. 


\section{DISCLAIMER}

This report was prepared as an account of work sponsored by an agency of the United States Government. Neither the United States Government nor any agency thereof, nor any of their employees, makes any warranty, express or implied, or assumes any legal liability or responsibility for the accuracy, completeness, or usefulness of any information, apparatus, product, or process disclosed, or represents that its use would not infringe privately owned rights. Reference herein to any specific commercial product, process, or service by trade name, trademark, manufacturer, or otherwise does not necessarily constitute or imply its endorsement, recommendation, or favoring by the United States Government or any agency thereof. The views and opinions of authors expressed herein do not necessarily state or reflect those of the United States Government or any agency thereof. 
DISClamisR

Portions of this docoment may be Illegible in electronic image products. Images are produced from the best available original docomenter 


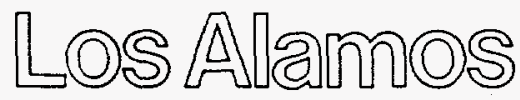

Los Alamos National Laboratory

Los Alamos, New Mexico 87545
July 31,1997

MST-4-97-30

Dr. Charles Sorrell

Program Manager

Office of Industrial Technology

US Department of Energy

EE-232, FORS

1000 Independence Avenue, SW

Washington, DC 20585

Dear Charlie:

Enclosed is the non-proprietary Annual Report for FY 1996 for the "Microwave Processing of Ceramic Oxide Filaments" program. Actually, it is the final report for this microwave project and for the 3M CRADA No. LA93C10078-A003. As such, this report summarizes the deliverables, experimental findings, presentations, and papers related to the CRADA.

As noted in the report, $3 \mathrm{M}$ is preparing to follow up the CRADA with further work using a commercial TWT-driven microwave system. I personally find this very pleasing, indicating that the project has demonstrated some industrial potential.

Thank you for your continuing support of our program over the last three years. I appreciate your efforts to keep the funding flowing for our proprietary work. Should you have any questions about this report and our CRADA project, please contact me at the Burke Medical Research Laboratory, Cornell University Medical College, in White Plains, NY, at 914-948-0050, ext. 2151.

Sincerely,

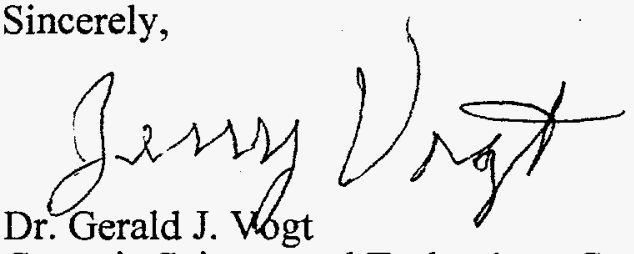

Ceramic Science and Technology Group

GJV:gjv 
Dr. Charles Sorrell

$-2-$

July 31,1997

MST-4-97-30

Cys w/enc:

Sarah Dillich, DOE/OIT

R. Lemons, MST-DO, MS G755

F.D. Gac, MST-4, MS G771

E. Joyce, CIT, MS D453

File (2)

xc w/enc:

Los Alamos

A. Regan, LANSCE-5, MS H827

A. Rohlev, LANSCE-5, MS H827

Externals

R.H. Plovnick, 3M

M.A. Leitheiser, 3M 


\section{PERMISSION TO PUBLISH}

TITLE MICROWAVE PROCESSING OF CERAMIC OXIDE FILAMENTS, ANNUAL REPORT, FY1997

AUTHOR Gerald J. Vogt

PUBLICATION Advanced Industrial Materials Program Annual Progress Report for FY 1996

\section{CIRCLE ONE:}

You (have) (do not have) permission to use the above information.
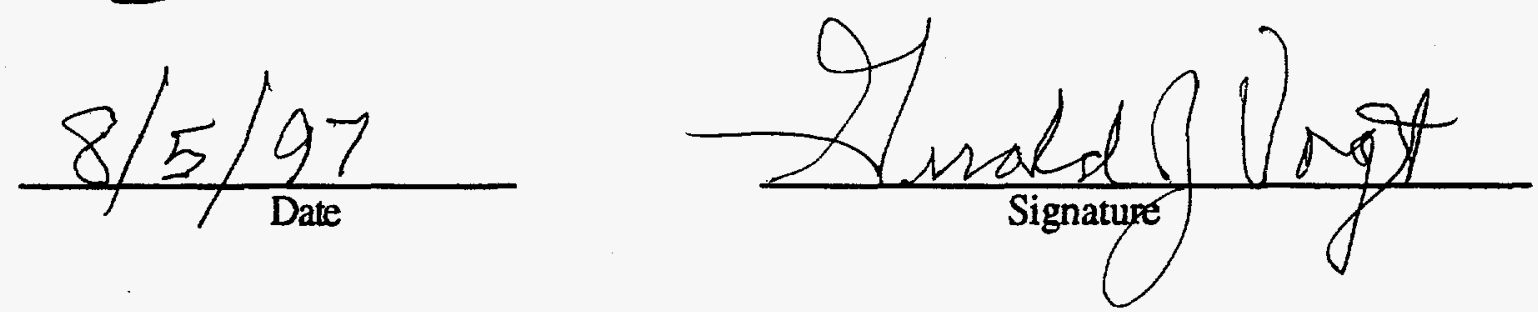
TITLE: MICROWAVE PROCESSING OF CERAMIC OXIDE FILAMENTS

FINAL REPORT, FY 1997

AUTHORS: Gerald J. Vogt, Ph.D.

SUBMITTED TO: Dr. Charles Sorrell

Program Manager

Advanced Industrial Materials (AIM) Program

U.S. Department of Energy

Office of Industrial Technology

EE-232, FORS

1000 Independence Avenue, SW

Washington, D.C. 20585 


\title{
MICROWAVE PROCESSING OF CERAMIC OXIDE FILAMENTS
}

\author{
Gerald J. Vogt, Ph.D. \\ Los Alamos National Laboratory \\ PO Box 1663 \\ Los Alamos, New Mexico 87545
}

\section{INDUSTRIAL SIGNIFICANCE}

The objective of the microwave filament processing project is to develop microwave techniques to manufacture continuous ceramic oxide filaments. Microwave processing uses the volumetric absorption of microwave power in oxide filament tows to drive off process solvents, to burn out organic binders, and to sinter the dried fibers to produce flexible, high-strength ceramic filaments. The technical goal is to advance filament processing technology by microwave heating more rapidly with less energy and at a lower cost than conventional processing, but with the same quality as conventional processing. The manufacturing goal is to collaborate with the $3 \mathrm{M}$ Company, a US manufacturer of ceramic oxide filaments, to evaluate the technology using a prototype filament system and to transfer the microwave technology to the $3 \mathrm{M}$ Company.

Continuous ceramic filaments are a principal component in many advanced high temperature materials like continuous fiber ceramic composites (CFCC) and woven ceramic textiles. The use of continuous ceramic filaments in CFCC radiant burners, gas turbines, waste incineration, and hot gas filters in U.S. industry and power generation is estimated to save at least $2.16 \mathrm{quad} / \mathrm{yr}$ by year 2010 with energy cost savings of at least $\$ 8.1$ billion. By year 2010, continuous ceramic filaments and CFCC's have the potential to abate pollution emissions by 917,000 tons annually of nitrous oxide and 118 million tons annually of carbon dioxide (DOE Report OR-2002, February, 1994).

Woven textiles are used in hot gas filtration, high-temperature insulation in aircraft firewalls and engine cowls, zone dividers and furnace curtains in metal processing, oil boom covers to burn off oil spills, and many other applications. Seamless ceramic fiber filter bags can operate up to $1100^{\circ} \mathrm{C}$ to remove more than $99.9 \%$ of the pollution particulates in a variety of corrosive gas environments. Annual energy savings of $0.1 \mathrm{quad} / \mathrm{yr}$ are possible from the combustion of coal alone. Hot gas filters will reduce nitrous oxide and carbon dioxide emissions by thousands of tons annually. Filtered hot gas will also help prevent erosion of turbines.

\section{TECHNOLOGY TRANSFER}

A Cooperative Research and Development Agreement (CRADA), entitled "Microwave Processing of Continuous Oxide Ceramic Filaments," was established with the 3M Company, a manufacturer of continuous ceramic oxide fibers. The agreement was signed on October 22, 1993. This agreement will be the direct means of transferring this microwave technology to $3 \mathrm{M}$. 


\section{PROJECT SCOPE}

The microwave filament processing project comprised high-risk experimental work in exploring the advanced application of microwave processing in manufacturing ceramic oxide filaments. This exploratory work was at the cutting-edge of microwave processing of ceramic oxide filaments. This cutting-edge work was possible through the collaborative work between experts in filament spinning $(3 \mathrm{M})$ and in microwave heating and technology (Los Alamos).

The three-year project consisted of three phases. In the first year (FY94), we examined the feasibility of sintering of prefired (to burn out organic material) filament tows as phase $\mathrm{I}$. Because of technical difficulties, the sintering work continued into the second year. We looked at the feasibility of high-temperature dielectric measurements with collaboration of measurement expert, subcontracted with Los Alamos. In the second year (FY95), we started the phase II work on the potential of microwave drying single filaments and multiple filaments, spun from a $3 \mathrm{M}$ proprietary alumina-based sol. In the third year (FY96), we changed original work scope of phase III to investigate a potentially important industrial process that was discovered in the second year of the project. We worked on the new process rather than microwave-driven filament prefiring as originally planned.

The major deliverables for each project phase and at the conclusion of the project included the following:

1. Samples of the microwave processed filaments for comparison to conventionally processed filaments at $3 \mathrm{M}$.

2. Technical quarterly reports and an annual report submitted to $3 \mathrm{M}$, summarizing the experimental conditions and results of the microwave processing.

3. Video tapes demonstrating the real-time visual effects of microwave processing.

4. Progress meetings either at Los Alamos or St. Paul.

5. Technical data and reports on the feasibility of measuring the dielectric properties of prefired and fully-processed zirconia-based filament tows.

6. Consultation on choosing a commercial microwave system to continue development of microwave processing at $3 \mathrm{M}$.

7. Delivery of an electronic frequency controller to be used with the microwave system purchased by $3 \mathrm{M}$.

The major deliverables were met, although not always on time due to the technical difficulties encountered during this cutting-edge experimental work. The project was not completed on time due to the major illness of the Los Alamos principal investigator. The project halted in June, 1996, and restarted in FY97. The CRADA was extended into FY97 and completed by June 22, 1997. 


\section{TECHNICAL SUMMARY}

\section{Sintering-Phase I.}

1. We demonstrated the ability to heat continuously a moving filament tow to sintering temperatures $\left(>1000^{\circ} \mathrm{C}\right)$. This ability is critical for the industrial processing of continuous filaments.

2. We proved the concept of hybrid heating for ceramic filament tows of low dielectric loss by lightly coating the tow with a high loss material (e.g. carbon). The lossy coating allows the tow to heat to sufficient temperature to increase its dielectric loss and the microwave absorption of the tow. This technique broadens the range of different ceramic oxides that can be heated by microwave processing.

3. We developed the practical application of a microwave tube furnace technique as a universal method to stably heat low loss fibers susceptible to thermal runaway by microwave heating. Specific ceramic oxides exhibit a near exponential increase in dielectric loss with increasing temperature. Tows of such materials do rapidly and uncontrollably heat to melting because the heating rate increases with temperature in a positive feedback loop. Also, this method can be used to heat very low loss fibers without hybrid heating by coatings.

4. We experimentally observed the importance of the electromagnetic interactions between the electric field in the microwave cavity and the heated fiber tow. Such interactions must be included in any numerical models of complex microwave system.

5. We discovered that high temperature measurements of the complex dielectric constant for zirconia-based filaments must be done using electrical resistive heating. Even so, the dielectric measurements of filaments will still be complicated by significant change in the dielectric constant with the first several heating cycles. The use of microwave heating during dielectric measurements is not practical due to extremely nonuniform heating of the sample.

\section{Drving-Phase II.}

1. We demonstrated continuous spinning and drying of a collectible continuous single filament. This demonstration is critical for an industrial process.

2. We microwave-dried large diameter, shaped filaments in a continuous process. The filament diameters are significantly larger than those currently commercial processed. Filament shapes include flat ribbon and dog-boned cross-section.

3. We prepared multiple filaments by simultaneous, continuous spinning from a multiple-hole spinneret. This step demonstrates the potential for the scale-up needed for manufacturing.

4. We operated the microwave drying system for many hours, only limited by the load size of sol in the spinneret. Again, this is a significant step toward scale-up.

\section{Novel Microwave Process-Phase III.}

1. We discovered a unique process of industrial importance to form novel ceramic items by processing spinnable sols. The process produces a ceramic product that is not easily made by radiant heating. These ceramics represent a potentially new product line for the $3 \mathrm{M}$ Company. 
2. We demonstrated a continuous and reproducible process to produce the novel ceramics in a single mode microwave cavity driven by a Traveling Wave Tube (TWT). Application of the TWT amplifier in materials processing is a new area in microwave development. The TWT is a variable frequency microwave source that is readily adaptable for process control.

3. We utilized a spinneret with a larger sol capacity to show that the process can be run for longer than several hours. The new process with the experimental applicator was run for more than ten hours, only limited by the load capacity of the spinneret. This work demonstrates great potential for scale up to an industrial process.

4. We carried out this work with a $3 \mathrm{M}$ proprietary alumina-based sol. Operating was quite easy with this sol. We believe that it can also be easily done with other ceramic-based sols.

5. Our experiments with a quickly formulated titania-based sol demonstrated the importance of the sol properties. Successful processing is strongly dependent on the drawability of a ceramic-based sol.

6. We found that the process can be performed with a Magnetron-driven single mode cavity operating at $2.45 \mathrm{GHz}$. We examined the process in two different cavities, designed to operate in either a $\mathrm{TE}_{10 \mathrm{n}}$ or $\mathrm{TM}_{010}$ mode. Our study pointed out that complex and expensive cavities with continuous, rapid mechanical tuning would be necessary for continuous, stable operation.

7. We can run the process in a multimode cavity driven by a TWT amplifier under precise operating conditions. An example of a multimode device is the commercial kitchen microwave oven driven by a Magnetron. A process could be devised with a multimode applicator, but the system would have poorer energy efficiency than a single-mode system by one or two orders of magnitude.

\section{Microwave Instrumentation}

1. We designed, developed, and operated a very stable and robust TWT-driven microwave system for processing continuous ceramic oxide filaments. This microwave system was used in all phases of the project.

2. We designed and fabricated a rapid electronic tuning circuit for the TWT amplifier that maintains the cavity at resonance and regulates the cavity power level. The controller circuit allows a rapid and robust microwave process that stably operates with rapidly changing loads or material properties. The circuit is relatively simple, using readily available commercial components.

3. Our use of TWT microwave source permitted the design and use of simple microwave applicators without the need for complex moving mechanical parts to tune the applicator. This represents substantial savings in the cost and design time for the microwave cavity. This work could be done as well with a Magnetron source, but the TWT amplifier proved to be quite compatible with a simpler cavity design and faster implementation of system modifications.

4. We designed and operated a five foot long cylindrical cavity to increase the residence time of the drying continuous ceramic oxide filaments in microwave field. The cylindrical geometry offers energy efficiency by aligning the moving filament with electric field within the cavity.

5. Our drying cavity design allowed for the continuous input and output of product, an essential feature for an industrial process. The continuous product was funneled out of the cavity by 
means of a cutoff waveguide choke, an open cylindrical structure with smaller diameter than the cavity. The choke attenuated the microwave transmission without significant radiation leakage, while allowing the product to drop out of the cavity.

6. We utilized commercial CCD cameras to visually observe the microwave processing in realtime and to video record the microwave operation for post-processing diagnostics. Both video and audio recordings of the microwave process were also excellent tools to provide $3 \mathrm{M}$ technical personnel and management with visual demonstrations of microwave system.

This project demonstrated the superior process control and adaptability of a variable-frequency TWT microwave source for microwave processing of continuous oxide ceramic filaments. The CRADA included funds-in money from $3 \mathrm{M}$ to cover the materials and labor costs to fabricate special microwave components for $3 \mathrm{M}$. We have decided to return the funds-in money to $3 \mathrm{M}$ to purchase a complete, operable TWT-driven microwave system from a new industrial manufacturer. The project contributed to the $3 \mathrm{M}$ knowledge on the use of variable frequency TWT amplifiers in materials processing.

\section{M CONTRIBUTIONS}

The 3M Company contributed their expertise on filament spinning and the many test samples used throughout the project. The 3M Company provided Los Alamos with a suitable spinneret and on-site training by $3 \mathrm{M}$ personnel on the use of the spinneret. The spinneret included different extrusion plates and a release agent necessary for proper operation. The extrusion plates allowed us to spin different diameter filaments and to simultaneously spin different numbers of filaments. An alumina-based sol was also supplied in three separate lots during the project. This sol was used extensively in Phases II and III. 3M also provided the formulation and necessary chemicals to prepare the titania-based filaments.

The 3M Company prepared and delivered many different filament samples used during the sintering work in Phase I. The test samples included both prefired and fully processed samples of alumina-based and zirconia-based filaments. The $3 \mathrm{M}$ Company also furnished a filament winding apparatus to collect long continuous filaments.

The 3M Company will continue the work initiated in the project with a TWT-based microwave system from Lambda Technologies and with a Los Alamos frequency control circuit usable with the Lambda TWT system.

\section{CONCLUSION}

The project objective was to explore the feasibility of microwave processing for continuous ceramic oxide filaments for potential application in ceramic filament manufacturing. Because we found that feasibility for microwave sintering of filament tows was strongly dependent on the filament dielectric properties, we devised a microwave tube furnace as a universal method for sintering. We successfully dried spun single filaments of small and large diameters and multiple 
filaments, in a specially designed cylindrical cavity with a five foot length to increase the filament residence time. We discovered a novel ceramic product of commercial potential that can be prepared due to the special heating properties of microwaves. We demonstrated the superior process control and adaptability of a variable-frequency TWT microwave source for microwave processing of continuous oxide ceramic filaments.

\section{ACKNOWLEDGMENT}

I wish to thank Amy Regan and Tony Rohlev plus Group LANSCE-5 (formerly AOT-5) for their many hours of help, for their microwave expertise, and, especially, for the enjoyment that they brought to the project.

\section{PUBLICATIONS AND PRESENTATIONS}

1. G.J Vogt, W.P. Unruh, and R.H. Plovnick, "Microwave Sintering of Continuous Zirconia Ceramic Fibers," Materials Research Society Symposium Proceedings Vol. 347, pp 551-555 (1994).

2. G.J Vogt, W.P. Unruh, and J.R. Thomas, Jr., "Experimental Observations of Thermal Spikes in Microwave Processing of Ceramic Oxide Fibers," Materials Research Society Symposium Proceedings Vol. 347, pp 539-544 (1994).

3. J.R. Thomas, Jr., W.P. Unruh, and G.J Vogt, "Mathematical Model of Thermal Spikes in Microwave Heating of Oxide Ceramic Fibers," Materials Research Society Symposium Proceedings Vol. 347, pp 363-368 (1994).

4. G.J. Vogt, A. Regan, A. Rohlev, and M. Curtin, "Use of a Variable Frequency Source with a Single-Mode Cavity to Process Ceramic Filaments," Ceramic Transactions Vol. 59, The American Ceramic Society, Westerville, OH, pp 125-132 (1995).

5. G.J. Vogt, W.R. Tinga, and R.H. Plovnick, "Dielectric Property Measurement of Zirconia Fibers at High Temperatures," Ceramic Transactions Vol. 59, The American Ceramic Society, Westerville, OH, pp 227-234 (1995).

6. G.J. Vogt, A.H. Regan, A.S. Rohlev, and M.T. Curtin, "Use of a Variable Frequency Source with a Single-Mode Cavity to Process Ceramic Filaments," Proceedings of International Conference, Microwave and High Frequency Heating 1995, Cambridge University, Cambridge U.K., September 17-21, 1995.

7. G.J. Vogt, A. Regan, A. Rohlev, and M. Curtin, "Microwave Process Control through a Traveling Wave Tube Source," Materials Research Society Symposium Proceedings Vol. 430, pp 513-518 (1996).

8. A.H. Regan, G.J. Vogt, A.S. Rohlev, and M.T. Curtin, "Processing Ceramic Filaments in a Single-Mode Cavity with a Variable Frequency Source," Proceedings of 31st International Microwave Power Symposium, Boston, MA, July 28-31, 1996.

9. G.J. Vogt, A.H. Regan, A.S Rohlev, R.H. Plovnick, and M.A. Leitheiser, "Microwave Hybrid Heating of Ceramic Oxide Filaments in a Mullite Tube," to be published (LA-UR-96-2125). 


\section{AIM PRESENTATIONS}

1. G.J. Vogt, "Microwave-Driven Spray Drying and Filament Processing," oral presentation to Advanced Industrial Materials (AIM) Program, Annual Information and Review Meeting, Los Alamos, New Mexico, June 1-3, 1994

2. G.J. Vogt, "Microwave-Driven Spray Drying and Filament Processing," poster presentation to Advanced Industrial Materials (AIM) Program, Annual Information and Review Meeting, Los Alamos, New Mexico, June 1-3, 1994

3. G.J. Vogt, J.D. Katz, A.H. Regan, and A.S. Rohlev, "Microwave Processing of Ceramic Oxide Filaments," poster presentation to Advanced Industrial Materials (AIM) Program, Annual Information and Review Meeting, Washington D.C., June 14-16, 1995. LA-UR-95-1942.

\section{HONORS AND AWARDS}

"Recognition Of Excellence in achieving Industrial Partnerships" award, Los Alamos National Laboratory, Industrial Partnership Office, October, 1995.

\section{PATENTS/DISCLOSURES}

Two disclosures were made.

\section{LICENSES}

None.

\section{INDUSTRIAL INPUT AND TECHNOLOGY TRANSFER}

This project was performed under CRADA No. LA93C10078-A003 on "MICROWAVE PROCESSING OF CONTINUOUS CERAMIC-OXIDE FILAMENTS" with the 3M Company. The 3M Company intends to continue the work initiated in the project with the purchase of a TWT-based microwave system from Lambda Technologies and with a Los Alamos frequency control circuit usable with the Lambda TWT system. The project is completed.

\section{COST SHARING}

CRADA specifies a matching level of effort from the 3M Company, which has contributed its expertise in filament technology. The project has benefited greatly from the use of the state-ofthe-art microwave instrumentation available in the microwave processing laboratory in the Material Science Laboratory. 


\section{HIGHLIGHTS}

1. We devised a microwave tube furnace as a universal method for sintering. We found that the feasibility for microwave sintering of filament tows was strongly dependent on the filament dielectric properties, pointing to the need for a universal method of sintering.

2. We successfully dried spun single filaments of small and large diameters and multiple filaments, in a specially designed cylindrical cavity with a five foot length to increase the filament residence time.

3. We discovered a novel ceramic product of commercial potential that can be prepared due to the special heating properties of microwaves.

4. We demonstrated the superior process control and adaptability of a variable-frequency TWT microwave source for microwave processing of continuous oxide ceramic filaments.

5. Los Alamos delivered an electronic frequency controller, developed in this project, to be used with the microwave system purchased by the $3 \mathrm{M}$ Company. 
PROJECT SUMMARY

ADVANCED INDUSTRIAL MATERIALS (AIM) PROGRAM

PROJECT TITLE: MICROWAVE PROCESSING OF CERAMIC OXIDE FILAMENTS

PHASE: FY96

PHASE COMPLETION DATE: 6/22/97

PERFORMING ORGANIZATION(S): Los Alamos National Laboratory, 3M Company

PRINCIPAL INVESTIGATORS(S): Gerald J. Vogt (505) 665-4988, Ross H. Plovnick (3M) (612) 733-9454

PHASE OBJECTIVE: Develop a new microwave process with industrial potential.

ULTIMATE OBJECTIVE: The project objective was to explore the feasibility of microwave processing for continuous ceramic oxide filaments for potential application in ceramic filament manufacturing. The microwave filament processing project comprised high-risk experimental work in exploring the advanced application of microwave processing in manufacturing ceramic oxide filaments. This exploratory work was at the cutting-edge of microwave processing of ceramic oxide filaments. This cutting-edge work was possible through the collaborative work between experts in filament spinning (3M) and in microwave heating and technology (Los Alamos).

TECHNICAL APPROACH: Observe microwave interaction with various ceramic oxide filaments in different stages of processing. Modify microwave procedures and applicators to enhance microwave interaction and heating control.

PROGRESS: The novel microwave process was examined for efficiency with different configurations of applicator design and microwave source. A microwave system utilizing a TWT amplifier was found to offer the better process control and stability under continuous operation.

Presentations: $11 \quad$ Proceedings: 9 Awards: 1

\section{ACCOMPLISHMENTS:}

Licenses: None

Other Successful Technology Transfer Activities as Evidence of Industry Interest:

1. The 3M Company will continue the work initiated in this project with a TWT-based microwave system from Lambda Technologies.

2. Los Alamos has provided the $3 \mathrm{M}$ Company with a frequency control circuit usable with the Lambda TWT system. 
PROJECT SUMMARY

\section{ADVANCED INDUSTRIAL MATERIALS (AIM) PROGRAM}

PROJECT TITLE: MICROWAVE PROCESSING OF CERAMIC OXIDE FILAMENTS

CRITICAL ISSUES: The feasibility of direct sintering of ceramic oxide tows is strongly dependent on the dielectric properties of the oxide filaments.

FUTURE PLANS: The 3M Company will continue the work initiated in this project with a TWT-based microwave system from Lambda Technologies.

POTENTIAL PAYOFF: The novel microwave processing discovered and developed under this project has strong potential as an industrial process.

ESTIMATED ENERGY SAVING:

FUNDING HISTORY: 


\section{ADVANCED INDUSTRIAL MATERIALS PROGRAM LIST OF INVESTIGATORS PARTICIPATING IN PROJECT}

Project: Microwave Processing of Ceramic Oxide Filaments, G.J. Vogt

Reporting Period: Final Report, FY 1996-1997

Person Providing Information: Gerald J. Vogt

\begin{tabular}{|c|c|c|c|c|c|c|}
\hline \multirow[b]{3}{*}{ Name } & \multirow{3}{*}{$\begin{array}{l}\text { Type of } \\
\text { Position }\end{array}$} & \multirow{3}{*}{$\begin{array}{l}\text { Planned } \\
\text { Time on } \\
\text { Project } \\
\text { (days/week) }\end{array}$} & \multicolumn{4}{|c|}{$\begin{array}{l}\text { Changes from Planned on Project } \\
1 \text { st 2nd 3rd Entire }\end{array}$} \\
\hline & & & $1 \mathrm{st}$ & 2nd & $3 \mathrm{rd}$ & Entire \\
\hline & & & Qtr & Qtr & Qtr & Year \\
\hline G.J. Vogt & $\begin{array}{l}\text { Principal } \\
\text { Investigator }\end{array}$ & $2-3$ & $\mathrm{nc}$ & $\mathrm{nc}$ & $\mathrm{nc}$ & $\mathrm{nc}$ \\
\hline F.D. Gac & $\begin{array}{l}\text { Permanent } \\
\text { Staff }\end{array}$ & $0-1$ & $\mathrm{nc}$ & nc & $\mathrm{nc}$ & nc \\
\hline A.H. Regan & $\begin{array}{l}\text { Permanent } \\
\text { Staff }\end{array}$ & $0-1$ & nc & nc & $\mathrm{nc}$ & $\mathrm{nc}$ \\
\hline A.S. Rohlev & $\begin{array}{l}\text { Post-Doctoral } \\
\text { Student }\end{array}$ & $0-1$ & $\mathrm{nc}$ & nc & $\mathrm{nc}$ & $\mathrm{nc}$ \\
\hline
\end{tabular}

